\title{
Chapter 10 \\ The Interview in Migration Studies: \\ A Step towards a Dialogue and Knowledge Co-production?
}

\author{
Olena Fedyuk and Violetta Zentai
}

\subsection{Introduction}

The European migration research agenda, marked by an incredibly rich overlap of transnational social fields, brings various global and local trends, tightly overlapped, to its fore. The diversity of migration as an experienced and lived phenomenon, the multiplicity of work, welfare and citizenship regimes that often structure the move of individuals through European national and supra-national borders, and the histories of migratory trends and routes to and within various European states, all make the European context particularly diverse. It also signals the existence of intricate connections between various local conditions across the globe through the processes and histories of colonization, migration and globalisation. The interview, as one of the key methods in the broader qualitative research toolkit, and within migration research in particular, calls for a thorough epistemological scrutiny of its application, purpose, limitations and strengths. In this chapter we argue that the interview has great potential to unravel the "multi-layered links of global connectivity" (Castles 2012: 36) when applied with dynamic reflection on the contextual connections constituting the very core of migration research, the role of the researcher and the interviewed, and the power of knowledge production.

Even though the interview has been widely employed as a method to improve qualitative insight in various types of research, for migration studies, interviews have proved indispensable when researching vulnerable groups of people on the

\footnotetext{
O. Fedyuk $(\bowtie)$

University of Strathclyde, Glasgow, UK

V. Zentai

Central European University, Budapest, Hungary

e-mail: Zentaiv@ceu.edu 
move, and collecting data about various aspects of irregularity, grey economic activities, and the autonomy and agency of mobile people. As such, the interview has long been central to the design of ethnographic studies; however, it has also been increasingly used as an integral part of comparative case-study research, historical inquiries, and critical policy studies of migration. Interviews are often successfully integrated into wider qualitative inquiries, and used to obtain expert knowledge or elite opinions and political positions, thus departing substantially from the same method employed in ethnographic studies of non-elite, lower status or specifically vulnerable groups. As such, the interview needs to be carefully adapted to each data collection purpose, and to incorporate a reflexive reflection on the role of the interviewer and accompanying power dynamics.

In recent decades, the interview has also become essential to scholarly endeavours that pursue collaborative knowledge production and participant research. It has been used to carve a space directly for the respondents' voices and analysis of the situation, even though, as we will demonstrate later, this always remains contextual. As a method, various forms of interview allow for the unveiling of knowledge that otherwise would remain under the radar of formal surveys and other more standardized forms of data collection. Additionally, forms such as biographical and life story interviews, or unstructured interviews, allow the respondent to actively shape the research inquiry, and for the researcher to map out those areas not originally seen as part of the inquiry.

To understand the role of the interview in European migration research, this chapter first briefly outlines the distinct features of this method within the larger scope of qualitative methodology, and addresses the wider epistemological debate over the interview. Thus, we refer to the interview as a specific method within a broader qualitative methodological approach. This approach is situated at the crossroads of epistemological debates on power-invested knowledge production and the question of how methodology at large, and methods in particular, affect research outcomes and structure knowledge production. We then discuss how interviews have become particularly useful in certain areas of migration research, and revisit some of the main debates around interviewing techniques and roles within the interview setting, as well as the implications of these choices for research outcomes and data analysis. We have chosen to focus on and draw examples from the ethnographic traditions of interviewing, without undermining the wide use of interviews in a variety of disciplines exploring migration issues. The chapter concludes with a discussion of some challenges of interview use and data analysis, and suggests further potential contributions for more collaborative and reflexive research. 


\subsection{Outstanding Challenges and Complementarities of the Interview as a Method Within Qualitative Research}

In the migration field, the interview as a method rarely stands on its own; it is often combined with other methods, such as participatory or non-participatory observation, focus group discussions, or oral history and life-story data collection, in order to obtain a fuller understanding of the issues (see Morawska in this volume). Depending on the research purpose, there exists a great variety of interview formats, each adjustable to the needs of a particular inquiry, context and interview settings.

The most common format-based typology divides interviews into structured, semi-structured or unstructured interviews according to the rigidity of the interviewer's guidance on conducting a conversation with the respondent. Thus, the most structured interview often resembles the survey type, with all questions being written down in advance and duly asked at the interview appointment. Semi-structured interviews precondition a more open interview outline, which is often guided by the research interest or a particular topic of enquiry. Here, the interviewer ensures that respondents remain close to the topic, but often leaves enough space for the interviewee to open up the discussion and introduce connected topics, thus making it more exploratory in nature and cooperative in terms of knowledge production. Unstructured interviews are often a "luxury" of more observational and participatory research, where the researcher is able to spend sufficient time with the respondent and hold conversations in which it is the interviewee who largely structures the conversation. Depending on the type, interviews can contain open-ended or "yes/ no" questions, each offering different opportunities for data collection and interpretation.

As with other methods, it is crucial to bear in mind the type of data to be collected in an interview setting. Charmaz (2006) speaks of intensive interviewing as a form of "in-depth exploration of a particular topic or experience" that paves the way for interpretive inquiry (2006: 25), and juxtaposes it with informational interviewing used to collect exploratory data. Another distinction between the types of data sought is generated by how the individual narratives and reflections revealed in the interviews relate to the respondent's own life, often at the centre of the inquiry. Accordingly, the literature identifies "life-story," "oral history" and "biographical" interviews. As a specific form, "expert" interviews explore claimed expertise or entitlement to represent, say, an institutional position or reflections thereon, in addition to collecting information not easily obtained from written sources. In each case, an interview embraces a conversation, in which the interviewee shares her/his experience, opinions, memories, and knowledge, while "the interviewer is there to listen, to observe with sensitivity, and to encourage the person to respond" (Charmaz 2006: 25-26). As such, this calls for special reflexivity around power dynamics in such a setting, and a high ethical benchmark (see Iosifides, Chap. 6 in this volume, in particular Sect. 6.4). 
Not dissimilar to the other qualitative research methods such as focus groups, observation, and discourse analysis, the role of the researcher becomes an integral component of the method, be it through proximity of the contact established and the level of intimacy reached in an interview setting, or through a symbolic role the interviewer might (in)voluntarily represent by her/his association with a certain class, gender, nationality or race. The success of the interview as a method can depend on any or a combination of the above factors, in addition to being affected by the location, timing and setting of the interviewing process. It therefore requires particular reflexivity concerning the researcher's positionality when conceiving, collecting and interpreting data.

The interview method is often critiqued for collecting unrepresentative and freefloating interpretive data, even in post-positivist social sciences. What does it then mean that data collected at the interview should not be taken at face value? The interview should not be used primarily to collect "hard facts", but rather to guide a researcher through relevant issues in the field, collect data about lived experiences, knowledge, opinions and perspectives, and links between the individual and the collective that will help the researcher to understand and draw her/his conclusions about the field or a specific research question. Even expert interviews on the most seemingly neutral and technical details of events, laws, decisions, and so on, include implicit opinions, silences, accents, and reasoning that rarely render information "pure facts". In return, the interview method offers the richness of experience and thickness of ethnographic data that cannot be reached solely via the researcher's observation, discourse analysis, or the regulated format of a focus group. In all its manifestations, the interview is used as a method that allows for a reflexive mastering of research, sensitive to the transformation and adjustments of the original design in the light of new information and discoveries (Charmaz 2006). It is not surprising that the interview has become integral to the grounded theory approach, in which it is incorporated into step-by-step adjustment of the research design and conceptual advancement throughout the research process (see more on grounded theory by Barglowski in this volume). We will now discuss the specific way in which the interview has been instrumental in developing new paradigms in European migration studies.

Such considerations can help significantly while structuring interviews and choosing the type of questions to be asked. Understanding the purpose of the interview in research design is crucial: does it serve to obtain expert opinion, demonstrate an opinion, convey a lived experience and perspective, or explore the potential issues in the field? The interview structure will significantly depend on the researcher's level of access and positionality in the field; in certain situations, it is better to try to establish contact with the respondents by letting them lead the conversation, and occasionally try to guide it in a certain direction. This interview style grants a greater sense of empowerment and control to the respondent, who can choose her/ his own words to articulate their experience and knowledge, without the need for such experience being framed in the researcher's agenda and words. In other settings - and this is more common for expert interviews -, a well-(semi-)structured interview can make a good impression on the interviewed expert in the field and also 
ensure that the researcher covers all aspects of the problem. In both cases, it is important to remember that conducting an interview not only helps to acquire information or opinion, but also opens up neglected areas and directions in the research design, and points to directions and issues overlooked by the researcher. It is thus better to avoid survey-like "yes/no" type questions, and instead use questions that leave the interviewee enough freedom to shape the direction of the inquiry, rather than following a rigid structure proposed by the interviewer.

\subsection{When and How Can Interview Techniques Serve European Migration Research?}

In the context of qualitative migration research, the interview has been frequently used to: (a) access vulnerable populations, especially those with liminal regularity or functioning within the grey areas of economic and legal status; (b) provide an open-ended research agenda that can swiftly adjust to and incorporate new issues and directions that emerge during the research; and (c) provide an avenue for more cooperative research in which the respondents' perspectives and interpretation are incorporated more directly into the research outcomes, which can ultimately lead to the co-production of knowledge. We will now briefly summarise some examples of these three main applications in European migration research.

\subsubsection{The Interview as a Tool to Reach Vulnerable Migrant Populations}

Interviews became a key methodology when researching individuals with liminal legal status, or undocumented migrants (Wills et al. 2010; Ruhs and Anderson 2010; Anderson 2000). Furthermore, there are many other reasons that make a migrant population particularly vulnerable, or difficult to reach or survey. For example, it is often extremely challenging to reach people who have a perfectly legal status, but work in precarious settings in which their lifestyles and daily routines are severely affected by demanding work conditions and schedules. Conducting research with means other than the interview can prove very difficult in sectors such as night shifts and live-in domestic service, logistics centres, food processing farms, construction sites and seasonal agricultural jobs. The volume Global Cities at Work edited by Wills et al. (2010) focuses on the role of employment and immigration regimes in creating what the authors term a new class division of the low-paid migrant workers who keep London afloat, using interviews with workers in five low-paid sectors: cleaning, hospitality, construction, domestic care and food processing. Combined with historical analysis, the book succeeds in showing not only migrants' individual lives and trajectories, but also offers a sharp critique of the emergence of low-paid 
economy in a global city, with issues of race, gender, ethnicity, and immigration status reinvented in such labour market divisions.

The interview continues to play a major role in exploring the vast and fastgrowing care- and domestic labour market in Europe (Anthias and Lazaridis 2000; Keough 2016; Cuban 2013; Lutz and Palenga-Möllenbeck 2011). Here, the interview as a method helps not only to access migrant populations (mostly women) working in the shadows of private homes and closed care-institutions, but also, importantly, helps to untangle the meaning and practice of "love and caring mix with power and agency in the labour-for-money exchange" (Keough 2016: 31) that characterizes this job sector, one that is usually hidden from the public gaze. A further example of interview usage in research into stereotyped or stigmatized forms of migrant labour is Irene Peano's investigation into sex work (2013), which reveals the complex world of labour bondage and support networks within Nigerian prostitution networks in Italy. Van Liempt and Bilger in this volume discuss puzzles and methods of qualitative research conducted among 'smuggled migrants'.

For all the above-mentioned migrant workforce sectors and groups in Europe, organizing a focus group, conducting a survey or accessing the workplace for observation, is often next to impossible. Because the interview is flexible, it can be conducted at a convenient time or on neutral territory, where the respondent feels safe to express her/his views without repercussions. The interview allows the researcher to delve into respondents' experiential and interpretative worlds, and to account for the shifting situational practices, networks and identifications specific to the combination of precarious work and migration. In such research areas therefore, one has to be particularly aware of the interview conditions, place and time, all of which can affect the respondent's degree of openness.

\subsubsection{The Interview as a Method That Allows Researchers to Develop an Open-Ended Research Agenda}

Semi-structured and unstructured interviews in particular can be used to keep a research agenda open-ended and allow respondents to hint at possibly omitted areas of inquiry. This approach is often used in the exploratory or research design stage, but not only here; in fact, it often becomes integral to building new perspectives. In their insightful volume Women Migrants from East to West: Gender, Mobility and Belonging in Contemporary Europe, Passerini et al. argue that "the interviews provide us with theoretical reconsideration of the assumptions attached to the term migration" (Passerini et al. 2007: 3). The authors thus stress the role played by the interview as method in shaping the transnationalist turn in migration scholarship in the 1990s, and "understanding migration practices in cultural, political, civic and economic terms" (2007: 3). Using interviews and life stories with Bulgarian and 
Hungarian migrant women, and Italian and Dutch native women, the authors employ a unique, targeted use of the interview as method: the academic team makes use of the very same interviews collected during the research, but interprets them from different perspectives in each chapter. Explaining their methodological choices, the authors remind us that "the cultural stratifications of memory, ideology and experiences converge to compose complex narrations that correspond in an indirect way to the complexities in the social processes of geographical mobility" (2007: 6). With this interpretive work, the authors create a finely tuned picture of subjectivities situated in specific institutional and inter-subjective settings, and the encounters between migrant and native women.

A further example worth highlighting is a recent research with Polish fathers in Ireland and Poland. Conducted by female researchers who responded to the neglect of fathering experiences in transnational migration, this research focused on "fathering narratives, practices, and projects of migrant men" (Kilkey et al. 2014: 178), utilizing inquiry design and questions typically used in researching motherhood and its transnational practices. The study shows that when asked the same questions usually asked of women, men do reflect on and actively engage with issues of distant fatherhood, despite the relative silence in migration studies on these issues (Kilkey et al. 2014). These examples reveal one of the main advantages of the interview as a method: it creates possibilities for expanding and refining one's original research agenda, adding previously unnoticed elements into research design, while gaining a fresh perspective on the roles and perspectives of the actors.

\subsubsection{Action Research and the Interview as a Part of Complex Representations}

The interpretive nature of data collected through interviews, and the need for close cooperation with the respondent, have been highlighted by advocates of collaborative and action research. In these endeavours, the voice of the respondent is incorporated as an integral part of knowledge production, so that the researcher can make a direct impact on the respondent's situation. Accordingly, interviewing can be used as a platform for interviewees' more direct claim-making, or sharing a political standpoint or insider's knowledge on their "side of the story." It is not uncommon for such research to be combined with forms of communication other than written texts to facilitate wider social outreach. Examples of such interview use in European migration research are many, and most of them aim at foregrounding the autonomy of migrating and mobile populations, articulating political voice and alternative forms of organisation, and generating mobilization and solidarity. Such projects carry the potential for the interviewer to challenge existing migration and border regimes, labelling and fragmentation of the integrity and rights of migrating individuals, and elevating the migrants' voices to the contested politics of mobility (Squire 2011; Papadopoulos and Tsianos 2013). 
There are a growing number of collaborative projects that use interviews to bring the voice of the respondent closer to a wider audience. Often, these are textual-visual, video and interactive online projects that also push disciplinary boundaries and help represent populations which otherwise remain silent or of weak voice. Here, it is worth mentioning a number of quite diverse projects. The London-based cooperative Angry Workers and Labournet TV used filmed interviews with workers, activists and trade unionists to document and support the labour struggles of migrants in Italian logistics centres (Ditching the fear, 2015). The visual-textual project Work is Elsewhere followed 16 mobile workers of different backgrounds moving across Europe from their homes to their workplaces. The in-depth interviews with each migrant, their families and co-workers built a base for the narratives, accompanied by professionally-shot photographs. Interviews also became the basis for at least two archives of migrants' voices and memories in Europe. One project, Narratives and Images from the Lives of Migrants in Greece (2004-2008), created a photo album of Albanians taking part (or contributing photographs from family albums), and uses excerpts from their interviews to illuminate their experiences of work, the historical transformations of the region, and migration histories. Another more recent project, the Archive of Migrant Memories (started in 2012), uses films made by migrants in Italy, and specifically Lampedusa, as a way to coproduce video memories about or by mobile people.

European migration research has shown a rise in the number of such projects since the so-called refugee crisis, when it became particularly important to create platforms for more collaborative knowledge production about mobile populations. Syriani in Transito is a photo-textual project that collects the stories of young Syrian refugees. The interactive online project I am a migrant features video portraits and interviews with successful immigrants across the world. Problematic as they may seem from the methodological perspective, these projects combine a variety of media, including film, animation, photo-exhibitions, interactive online documentaries, and emotional cartographies of the migration routes and urban landscapes. While we do not claim here that interviews played a central role in all these projects, we include them as an intriguing inter-disciplinary and inter-media exercise in which interviews were combined with other methods beyond a strictly academic research purpose (see a rich discussion on media and digital technology based research on migration by Leurs and Prabhakar in this volume). The various ways of using interviews and interview techniques in such projects can serve as a sensitive way to engage migrants in political and social struggles, build bridges within communities and help people process their experiences in a more positive, affirmative way. 


\subsection{The Role of the Researcher in the Interview and Interpretation of Collected Data: Epistemological Questions}

The interview's methodological strength stems from the rich potential of a one-onone conversation with a respondent, and the opportunity to refocus and adjust the scope of inquiry as the interview unfolds. These are possible, however, only due to the prominent role of the researcher throughout the interview: from deciding on the scope of the inquiry, through the selection of respondents, setting the "rules" and structure of the interview, to devising the questions, and registering, storing and interpreting the respondents' data. All this indicates the influence of researcher's position on the nature and scope of data, and its analysis. This is not to say that the researcher's position undermines the credibility of research or produces purely subjective results; it is, however, essential to be aware of and reflect upon the researcher's role and position in all major stages of the research.

While multiple methodological and conceptual attempts exist that speak constructively of the power dynamics within interview settings and data interpretation, in migration studies, the main epistemological debates centre on the concept of the researcher as an insider or outsider to the researched group (Song and Parker 1995; Ryan 2015; Williams 2015; Chereni 2014; Carling et al. 2014). The most influential critics have addressed specifically: (a) the role of the ethno-national lens (Amelina and Faist 2012; Glick Schiller and Caglar 2009; Carling et al. 2014); and (b) the role of gender (Anthias and Lazaridis 2000, Mahler and Pessar 2006, Passerini et al. 2007) in constructing insider or outsider categories. Other scholars of the insider/ outsider dilemma propose the establishment of "multiple positionalities" to challenge the fixed constructions of "insiders" versus "outsiders" in the research process (Ryan 2015). These positionalities may be found through reflecting upon gender, age/generation, parental status and migratory experiences, as well as the intersections of these, for both the interviewer and interviewees.

\subsubsection{Who Is an Insider or an Outsider in an Interview, and How Does It Matter?}

The presumption in migration research that the interviewer is an insider (belonging to the same ethnic or national group) rests heavily on the methodological nationalism perspective and the ethnic lens (Wimmer and Glick Schiller 2003, Glick Schiller and Caglar 2009). Accordingly, when a researcher shares the same ethnic or national background as the researched group or individual, it is assumed that $\mathrm{s} / \mathrm{he}$ becomes an insider to the perspectives and/or social positions of the researched. This, 
allegedly, helps to obtain more intimate and authentic knowledge. The transnationalist perspective denounces the centrality of nation-states' territorial and institutional boundaries in shaping the migrants' and researcher's identifications, and theorizes the importance of the simultaneous and multiple embeddedness of transnational migrants in various roles and groups across borders (Glick Schiller and Caglar 2008, 2011; Caglar 2007). Amelina and Faist (2012) emphasize the rigidity of the ethnic lens-based approach and call for de-naturalizing the assumed roles based on nationalities through reflexivity and multilocality (2012). The authors suggest that the multilocality approach encourages not only research in multiple locations, but also a multiplicity of perspectives and belongings (religious, political, and/or social), all of which can guide situational activities and representations when interviewing both migrants and non-migrants (Amelina and Faist 2012).

Song and Parker (1995), focusing on the methodological implications of conducting research among Chinese immigrants in Britain, express their frustration with the oversimplified categorization of insider/outsider in migration research, arguing that it hampers research on at least two levels. On the one hand, it neglects diversity within groups to which both researcher and the interviewee belong, while on the other, it "obscures the diversity of experiences that can occur between the researcher and the researched" (Song and Parker 1995: 243). In their conceptualmethodological reflection on conducting research with their co-ethnics "beyond the insider-outsider divide in migration research", Carling et al. (2014) advocate for a more nuanced approach to personality in research settings and propose a "third position" typology. This conceptual move broadens the range of the researcher's engagement and complicates the insider-outsider dichotomy. The proposed typology encompasses the positions of "explicit third party, honorary insider, insider by proxy, hybrid insider-outsider, and apparent insider" (2014: 1), all of which are based on the characteristics and markers of identity that are actively managed and manipulated in an interview or research setting (on challenges of categorisations see Jakobs in this volume).

Carling et al. (2014) describe how their Polish-born researcher, conducting interviews with Tamils in Norway, was first perceived as an ethnic outsider, but could gain interview access to a Tamil female respondent due to the fact that the former was visibly pregnant. The authors analyse the situation as shifting the "entire dynamics" in the setting: "This rather insecure informant became the experienced mother and older woman who could offer valuable knowledge and advice to the young researcher. The change in power relations in the interview context later spilled over into discussion of topics that were central to the research question" (2014: 19). Other studies have similarly emphasized that none of the single identities is sufficient to secure the insider position, with gender, class and age being among most significant markers. Different aspects of identification can become more prominent than others in an interview setting, thus making it essential not to cement methodological specifications according to social categories, but to incorporate them into the research design with critical reflexivity. Further, sophisticated gender reflexivity should not be limited to addressing the embodied gender experi- 
ence in an encounter between individuals. It also helps facilitate a discussion of gendered regimes at large, that is, the organisation of social relations, situations, and positions assigned according to gendered hierarchies, in which both interviewer and interviewee are embedded and conditioned.

We argue that understanding the interview encounter as flexible, situational and dynamic should inform research design and data interpretation. It is difficult for the researcher to encourage collaboration, to discover what is at stake for the interviewees, and to bring forth their situational narratives in an interview setting. It is also challenging to move beyond these situational encounters in the analysis, and understand what generates situational narratives. Each encounter brings a new negotiation of roles, and requires continuous checks and accountability on the distribution of social positions assumed in an interview (for a detailed methodological discussion, see the qualitative study with Zimbabweans in Johannesburg by Admire Chereni 2014).

\subsubsection{A Dynamic Approach to the Identity of the Researcher}

In her reflections, Ribbens (1989) calls the interview "an unnatural situation" in which there is an imbalance between one person speaking at length about their lives and experiences, faced with another person, just briefly introduced, and "collecting" the information. Several authors advocate for managing, rather than simply assuming, one's perspective and role in the interview situation. This embodies an important shift towards reflexivity as a main "check point" in the research, where neither the role of the researcher nor that of the interviewee can be assumed. Ryan (2015) proposes a concept of "multiple positionalities" and suggests that "interview processes should be understood in terms of the dynamic rhythms of multi-positionalities" (2015: 2), rather than an encounter between insiders and outsiders. Razon and Ross (2012) and Ryan (2015) use the metaphor of a "power dance" in the research encounter, where "the interviewer is trying to place the interviewee, but at the same time, the interviewee is also trying to position the researcher" (Ryan 2015: 5). In this dynamic approach, gender and ethnicity, age, class and religion, are not "standalone dimensions of who we are", but "ingredients in a complex and active mix of identities" (Ryan 2015).

To remain reflexive about power relations without becoming lost in the fragmentation and detail of a situational identification and encounter, we find two concepts particularly fruitful. One stresses the issue of empathy, referring to "how we listen" (Ribbens 1989: 586), while the other centres on performativity: here we refer to Hochschild's (1983) interpretation of deep acting. Based on her reading of Erving Goffman and Konstantin Stanislavski, she explains how we attune our social interactions based on our beliefs and situational encounters. Reflecting on her multi-year research with migrants from Polish and Irish backgrounds in the UK, Ryan (2015) emphasises the role of empathy and rapport in an interview setting and data analy- 
sis. She approaches both empathy and rapport as active notions, requiring negotiation "through positionalities of gender, age/generation, parental status and migratory experience as well as nationality" (2015: 2). She argues that "interview processes should be understood in terms of the dynamic rhythms of multi-positionalities." She argues that this approach enables researchers to be reflexive about the contingency of empathy, understanding and rapport that constitutes an interview situation. Further, "these need to be continually negotiated across layers of power differentials" (Ryan 2015: 3).

In migration research, telling a story (that is, performing a narrative of migration) plays a prominent role: it often becomes indispensable for the very possibility of mobility. Thus, in case of applications for visas, residence permits or asylum, success can be attained only when the applicant tells a story "recognizable" to the bureaucratic machine. A simplified narrative needs to be learnt, performed, and embodied. Performativity in this case enters the domain of what Hochschild calls "deep acting" (1983), when the individual trains her/his own feelings to believe and feel in a certain way. The presence of a researcher enquiring into one's migration story can often be (in)voluntarily identified by the interviewee as representing certain power structures, which can trigger a specific line of self-representation.

These two notions of how we listen (empathy) and how we tell our stories (performativity) offer a less-well explored but nevertheless intriguing line of thought beyond the insider/outsider debate. It has been noted that even being an ultimate insider can trigger a distance between the researcher and the researched. Certain forms of performativity can be viewed as a matter of shared understanding, thus leaving the performed roles unexplained. This caveat resonates with the notion of "cultural intimacy" (Herzfeld 1997) as "the recognition of those aspects of a cultural identity that are considered a source of external embarrassment but that nevertheless provide insiders with their assurance of common sociality" (1997: 3). Such intimacy can render certain topics taboo, in fear of violating a culturally shared sense of propriety, and thus lead to starker, more clichéd responses. By the same token, being a "perfect outsider" can trigger a certain freedom from the assumed shared norms, or open up new paths and agendas for research or the interviewee's personal interpretation.

\subsection{The Interview Within Research Design, Interview Data Processing and Interpretation}

\subsubsection{Mapping and Adjusting}

In a qualitative inquiry, research design often presents a variety and combination of methods; it is therefore important to approach time and other resources in a strategic way, leaving enough room for data processing. Ideally, a research project starts with mapping out the field, or even a pilot research project. It is during this stage that 
interviews can help to sharpen, broaden, or change the direction of the research inquiry based on preliminary findings. However, researchers often do not have the luxury of a pilot, and it is during the empirical research, or even afterwards, that they realise that the data points in a different direction, or that some questions remain unasked. It is therefore important to plan time for the adjustment of design and data-gathering methods. Adjustments can be pursued through repeated interviews with key (or the most interesting) respondents, or a follow-up Skype interview or correspondence, which is more likely when researching mobile populations. Such interviews are often called clarification or follow-up interviews, and while these sessions do not need to be as formal as the original interview setting, they usually aim to cover new ground that remained unnoticed during the first interview.

Adjusting research design can be a tricky and time-consuming process, which rarely reaches the methodology part of papers, and remains invisible in the final reporting. Each research adjustment tells its own stories of dead-ends and unexpected findings. For this reason, in this final content section of our paper, we turn to examples from our own fieldwork to exemplify some of the points. In particular, we will draw on an unpublished doctoral thesis available online, "Beyond Motherhood" by Olena Fedyuk (2011), in which over 80 semi-structured and life-story interviews conducted with Ukrainian domestic and care workers in Italy in 2007-2008 constituted one of the main data sources. Thus, in her methodology section, the author takes a specific epistemological position in saying that when conducting research with migrants, researchers often recount "success stories" by default, that is, those who made their migration project real, despite losses and hardships along the way. While researching such stories, we must pay equal attention to the silences around experiences, and to the gaps in narratives, closures and taboos in discussions. The author points out that her own position as a young Ukrainian woman in the field made it impossible for her to talk to her female respondents' husbands, most of whom were in their 40s and 50s. Similarly, the author discusses that when wanting to interview and compare mothers and children within one migrating family, she could only obtain good access and a trusting relationship with either the mother or the child, but never both. These frustrating fieldwork closures initially seemed to upset the research design for interviewing family units, yet pushed the author to rethink not only her access strategies but also the meaning of taboos within transnational families. It specifically led her towards one of the central themes in her thesis: the "politics" within the transnational family, in which the preservation of distance and performance was essential to maintaining peace within relationships affected by years of distance. It became key to exploring the unevenness of transnational connections and how members of these families negotiate their positions within internal hierarchies (Fedyuk 2011).

It is during these follow-up sessions that a researcher might come across new interpretations of their research problem, or a different research question altogether. These are, however, in a sense, true findings that make a research particularly innovative and practical. Without fearing productive adjustment, we suggest two 
strategies for adoption in research design and management. The first is to draw as detailed and thorough a picture of the research site/field as possible before the empirical research starts. This may involve outlining the main actors in the field (not only the group in the focus of the research, but possibly other actors and institutions that may affect the respondents' lives) by conducting a couple of exploratory expert interviews with actors or other scholars in the field. Drawing a map of such actors has multiple advantages: it can help to identify and access relevant respondents; it helps draw areas of interview inquiry towards the spheres of interaction between the actors; it can give a different perspective on the stories collected in the process of interviewing migrants; and it helps forge a more meaningful connection between the researcher and the field.

Second, we would like to emphasise the importance of reflexivity during data collection. By this we mean a critical questioning of the data, the conditions and circumstances under which it was collected, relationships in the field, and the positioning of the researcher. For this, we find it invaluable to keep a field work diary, where a researcher can note all particulars of the interview settings and encounters. Not only can this be an invaluable guide to later interpretation of the data, but, in some cases, can throw light on a specific interview setting or circumstances which can help analyse data, or even become data in itself.

\subsubsection{Data Processing}

The technical details of working with interview-generated data are discussed in various widely-accessible manuals (for example, Saldaña 2009). In brief, researchers are advised to record complex and longer interviews. Transcribing interviews is time-consuming, yet immensely useful, or in most cases, essential for data interpretation. The researcher should carefully consider whether s/he needs to transcribe an entire interview, or only selected portions that are highly relevant to the research question. Depending on experience and typing capacities, it is fair to suggest that $1 \mathrm{~h}$ of interview material takes at least $4-5 \mathrm{~h}$ to transcribe, but for beginners, the ratio could be $1: 10$.

Transcribed interview texts should be further processed for interpretation. Coding is an instrument for organizing and sorting data, a first step towards interpretation. Codes are used to label, compile and organize qualitative data. Codes may take the form of words, numbers or symbols assigned to particular points in the interview transcripts. Codes speak to the conceptual framework, research questions, or themes which derive therefrom. The coding scheme could be refined by adding, collapsing, expanding and revising the coding categories.

Increasingly sophisticated software programs, such ATLAS.ti, NVIVO, and QDA Miner, have been created to cope with the diversity and consistency of data collected in qualitative research. When applied mindfully, these programs help researchers through data analysis stages such as coding, grouping by themes, singling out patterns, and better and faster search management for quotes, themes and 
codes. ${ }^{1}$ However, it should be noted that software-based qualitative data analysis neither reduces the amount of data interpretation, nor does it make it more "objective". In principle, processing qualitative data from interviews using sophisticated software programs is very close to what was earlier done manually. Within the breadth of the recorded or transcribed material, a researcher needs to identify codes that reflect on the key research questions and themes, and then, within those, s/he needs to sort and organize the data relevant for those questions. Using software allows the researcher to group, compare, and relate the processed data in a faster and more comfortable manner than before.

Data collected in interview settings could be enhanced and enriched by a further combination of methods, including field observations, surveys, and focus group discussions. These efforts do not have to lead to verification of the information. Contrasting, cross-reading, and relating interpretations of differently-generated data are seen as the best avenues for the most productive use of interview-based information. Widely-used handbooks on qualitative research offer valuable guidance on diverse qualitative research methods, including more conventional and novel ones (for example, Denzin and Lincoln 2017).

\subsubsection{Data Interpretation}

Interpreting interview data is one of the most challenging aspects of the interview as a method; much of it, however, is embedded in reflexivity concerning the same epistemological questions and power dynamics that accompany the interview setting. Passerini et al. (2007), when elaborating on the oral history research they conducted among Italian, Dutch, Hungarian and Bulgarian women, reflect on the complex process of data analysis and interpretation: "The texts, which then form the data for our analysis, are thereby constructed by multiple interventions; first, the construction of the sample, itself through networks of different subjects, then the relationship between the interviewer and the interviewee, then the action of transcribers and translators, and finally the viewpoints of the reader in trying to analyse the account" (Passerini et al. 2007: 11). This detailed reflection on the layers of (in) voluntary interpretations underline how important it is for researchers to remain open and reflexive about each level of interpretation.

What can we achieve with reflexivity as an active research stance? We can: (a) avoid stereotypical and clichéd portrayals of the researched groups; (b) give the interviewees the opportunity to maintain their voices and views in the final representation of data (Amelina and Faist 2012); and (c) maintain awareness of data collection as an active process in which the positions of both researcher and interviewee are socially constructed and embedded. Such an ethical approach to the interview

\footnotetext{
${ }^{1} \mathrm{~A}$ useful review and guidance on the most often-used software-based qualitative data analysis tools can be found at: http://www.surrey.ac.uk/sociology/research/researchcentres/caqdas/support/ choosing/ (Accessed 18 December, 2017).
} 
method ensures that the findings of a qualitative inquiry are also understood as situational and influenced by the mutual positioning that interview encounters yield.

\subsection{Conclusions}

The European migration context offers a particularly diverse background for studies of human mobility. The dense overlap of national and supra-national political organizations, resulting in multi-layered migration, employment and welfare regimes, create a context in which migration per se cannot be sufficient to understand the experience of mobility, integration results, the sources of inequality for individuals and families with an immigration background, and the paths to overcoming such inequalities. It is important to consider and incorporate interdisciplinary perspectives in migration research, and use combined methodological toolkits which inform the findings and clearly address the main research questions outlined in the research design. The interview method can provide a flexible format for incorporating inquiries from a wide angle of perspectives, be it gender or citizenship studies, cultural studies or geography, religion or urban studies. The design and choice of the interview itself thus depends on disciplinary interests, research objectives, their role in the broader research design, and combination with other methods.

This chapter has demonstrated that in the European migration context, the interview is increasingly used as a research design component in a variety of areas and disciplines that enquire into human mobility. In particular, we have focused on the use of interviews in researching marginalised or vulnerable groups, in research settings where accessing informants using other qualitative methods has proven particularly difficult. We have also emphasised that the interview, often combined with various media formats, has been increasingly used as an advocacy tool, and as a first step towards collaborative research and knowledge co-production. Epistemological debates on the interview as a method cause us to rethink the division in which the interviewee is a source of raw data, and the researcher has the analytical capacity and expertise to turn this into data. As we have highlighted in Sects. 10.4 and 10.5 of this chapter, the researcher's position is just as situational, affected by positionality and vulnerable to contextual subjectivity as that of the respondent. This calls for special reflexivity on the setting and positionality of actors and power dynamics within the interview setting. In Sect. 10.5, we focused on the importance of openminded and critical evaluation of data collected through interviews, and the possible need for revision vis-à-vis the original research objectives and evaluation. A reflexive approach helps us examine whether the data really does answer the questions posed, which new and previously ignored research directions it opens up, and whether the original research design requires further clarification and adjustment. Only through integrating all these steps into data collection and interpretation can the interview fully realise its methodological potential. 


\section{References}

Amelina, A., \& Faist, T. (2012). De-naturalising the national in research methodologies. Ethnic and Racial Studies, 35(10), 1-18.

Anderson, B. (2000). Doing the dirty work? The global politics of domestic labour. New York/ London: Zed Books.

Anthias, F., \& Lazaridis, G. (2000). Gender and migration in southern Europe women on the move. Oxford: Berg.

Archive of Migrant Memories. http://www.archiviomemoriemigranti.net/progetti. Accessed 5 May 2017.

Caglar, A. (2007). Rescaling cities, cultural diversity and transnationalism. Migrants of Mardin and Essen. Ethnic and Racial Studies, 30(6), 1070-1095.

Carling, J., Erdal, M. B., \& Ezzati, R. (2014). Beyond the insider-outsider divide in migration research. Migration Studies, 2(1), 36-54.

Castles, S. (2012). Methodology and methods: Conceptual issues. In M. Berriane \& H. de Haas (Eds.), African migrations research: Innovative methods and methodologies (pp. 15-36). Trenton: Africa World Press.

Charmaz, K. (2006). Constructing grounded theory: A practical guide through qualitative analysis. London: Sage Publications.

Chereni, A. (2014). A methodological approach and conceptual tools for studying migrant belongings in African cities: A case of Zimbabweans in Johannesburg. Historical Social Research / Historische Sozialforschung., 15(1), 293-328.

Cuban, S. (2013). Deskilling migrant women in the global care industry. Basingstoke: Palgrave Macmillan.

Datta, K., Mcilwaine, C., Evans, Y., Herbert, J., May, J., \& Wills, J. (2006). Work, care and life among low-paid migrant workers in London: Towards a migrant ethic of care (pp. 1-37). London: Queen Mary, University of London.

Denzin, K., \& Lincoln, S. (2017). The SAGE handbook of qualitative research. London: SAGE Publications.

Ditching the Fear. (2015). 80 min Labournet. Tv Dir. Rosa Cannone/Johanna Schellhagen http:// en.labournet.tv/ditching-fear-0. Accessed 5 May 2017.

Fedyuk, O. (2011). Beyond motherhood: Ukrainian female labor migration to Italy (Doctoral thesis). Website. Accessed 15 Jun 2017.

Glick Schiller, N., \& Caglar, A. (2008). Beyond methodological ethnicity and towards the city scale: An alternative approach to local and transnational pathways of migrant incorporation. In L. Pries (Ed.), Rethinking transnationalism: The Meso-link of organisations (pp. 40-61). London: Routledge.

Glick Schiller, N., \& Caglar, A. (2009). Towards a comparative theory of locality in migration studies. Journal of Ethnic and Migration Studies, 35(2), 177-202.

Glick Schiller, N., \& Caglar, A. (Eds.). (2011). Locating migration. Migrants and cities. Ithaca: Cornell University.

Herzfeld, M. (1997). The cultural intimacy. Social poetics in the nation-state. New York: Routledge.

Hochschild, A. (1983). The managed heart: Commercialization of human feeling. Berkeley: University of California Press.

I am a migrant. http://iamamigrant.org/. Accessed 05 May 2017.

Keough, L. J. (2016). Worker-mothers on the margins of Europe: Gender and migration between Moldova and Istanbul. Bloomington/Washington, DC: Woodrow Wilson Center Press.

Kilkey, M., Plomien, A., \& Perrons, D. (2014). Migrant men's fathering narratives, practices and projects in national and transnational spaces: Recent polish male migrants to London. International Migration, 52(1), 178-191.

Lutz, H., \& Palenga-Möllenbeck, E. (2011). Care, gender and migration: Towards a theory of transnational domestic work migration in Europe. Journal of Contemporary European Studies, 19(3), 349-364. https://doi.org/10.1080/14782804.2011.610605. 
Mahler, S. J., \& Pessar, P. R. (2006). Gender matters: Ethnographers bring gender from the periphery toward the core of migration studies. International Migration Review, 40(1), $27-63$.

Narratives and Images from the Lives of Migrants in Greece. http://extras.ha.uth.gr/pythagoras1/ en/interview.list.asp. Accessed 5 May 2017.

Papadopoulos, D., \& Tsianos, V. (2013). After citizenship: Autonomy of migration, organisational ontology, and mobile commons. Citizenship Studies, 17(2), 178-196.

Passerini, L., Lyon, D., Laliotou, I., \& Capussotti, E. (Eds.). (2007). Women migrants from East to West. Gender, mobility and belonging in contemporary Europe. Oxford/New York: Berghahn.

Peano, I. (2013). Bondage and help: Genealogies and hopes in trafficking from Nigeria to Italy. In J. Quirk \& D. Wigneswaran (Eds.), Slavery, migration and contemporary bondage in Africa (pp. 225-251). Trenton: Africa World Press.

Razon, N., \& Ross, K. (2012). Negotiating fluid identities: Alliance-building in qualitative interviews. Qualitative Inquiry, 18(6), 494-503.

Ribbens, J. (1989). Interviewing: An “unnatural situation"? Women's Studies International Forum (Print)., 12(6), 579-592.

Ruhs, M., \& Anderson, B. (Eds.). (2010). Who needs migrant workers? Labour shortages, immigration, and public policy. Oxford: Oxford University Press.

Ryan, L. (2015). "Inside" and "outside" of what or where? Researching migration through multipositionalities. FQS 16, 2, Art. 17.

Saldaña, J. (2009). The coding manual for qualitative researchers. Los Angeles: Sage Publications.

Silver, C., \& Lewins, A. (2014). Using software in qualitative research: A step-by-step guide (2nd ed.). London: Sage Publications.

Song, M., \& Parker, D. (1995). Commonality, difference and the dynamics of disclosure in indepth interviewing. Sociology, 29(2), 241-256.

Squire, V. (2011). Politicising mobility. In V. Squire (Ed.), The contested politics of mobility: Border zones and irregularity (Routledge advances in international relations and global politics, pp. 1-16). Abingdon: Routledge.

Syriani in Transito. http://www.sirianintransito.com/. Accessed 5 May 2017.

Williams, K. (2015). Life narratives, common language and diverse ways of belonging. Forum Qualitative Sozialforschung/Forum Qualitative Social Research, 16(2), Art. 16, http://nbnresolving.de/urn:nbn:de:0114-fqs1502165

Wills, J., Datta, K., Evans, Y., Herbert, J., May, J., \& McIlwaine, C. (2010). Global cities at work: New migrant divisions of labour. London: Pluto Press.

Wimmer, A., \& Glick Schiller, N. (2003). Methodological nationalism, the social sciences, and the study of migration: An essay in historical epistemology. International Migration Review, 37(3), 576-610.

Work is Elsewhere. http://www.plotki.net/wie/article/31/map.html. Accessed 5 May 2017.

Open Access This chapter is licensed under the terms of the Creative Commons Attribution 4.0 International License (http://creativecommons.org/licenses/by/4.0/), which permits use, sharing, adaptation, distribution and reproduction in any medium or format, as long as you give appropriate credit to the original author(s) and the source, provide a link to the Creative Commons license and indicate if changes were made.

The images or other third party material in this chapter are included in the chapter's Creative Commons license, unless indicated otherwise in a credit line to the material. If material is not included in the chapter's Creative Commons license and your intended use is not permitted by statutory regulation or exceeds the permitted use, you will need to obtain permission directly from the copyright holder.

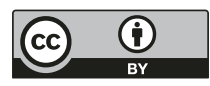

